\title{
Education and careers of European analytical chemists
}

\author{
Reiner Salzer • Philip Taylor • Nineta Majcen • \\ Evangelia Varella • Ioannis Kozaris
}

Published online: 17 October 2014

(C) Springer-Verlag Berlin Heidelberg 2014

What roles do analytical chemists play in the European labour force? Which chemical subdisciplines offer the most job opportunities? Does higher education in chemistry in Europe provide appropriate specialization for graduates? Reliable answers to these and other questions have been derived from the first European employment survey of chemists and chemical engineers, which was conducted in 2013. The American Chemical Society (ACS) regularly publishes an employment survey in Chemical \& Engineering News [1]. Data are collected from ACS members working in the USA. The survey results clearly show in which subdiscipline graduates received their highest qualification and in which subdiscipline they are working after starting their professional career. It would be of utmost interest for decisions within Europe for us to have access to similar data.

The questionnaire for the European employment survey of chemists and chemical engineers was jointly developed by all

Published in the topical collection celebrating ABCs 13th Anniversary.

R. Salzer $(\bowtie)$

Technische Universität Dresden, 01062 Dresden, Germany

e-mail: reiner.salzer@tu-dresden.de

\section{R. Salzer}

European Chemistry Thematic Network, Dresden, Germany

P. Taylor

Institute for Reference Materials and Measurements, European Commission Joint Research Centre, Retieseweg 111, 2440 Geel, Belgium

\section{N. Majcen}

European Association for Chemical and Molecular Sciences, Rue du Trône 62, 1050 Brussels, Belgium

E. Varella $\cdot$ I. Kozaris

Department of Chemistry, Aristotle University, 54124 Thessaloníki, Greece partners. The Web-based questionnaire has six general pages ("Personal", "Education", "Employment", "Job", "Training and "Salary"), which provide fields for free-text comments. Approximately 4500 responses were received. Industry employees ( $43 \%$ of all participants) found special questions on an additional page. Three per cent of the participants were self-employed. Only $3 \%$ of all participants were not employed or were seeking employment. Retired people submitted $2 \%$ of all responses. Thirty-nine per cent of all participants were women. The median age of all participants was 38 years. The youngest responders were aged 20 years. The oldest participant was an 87 -year-old woman.

Participation in the survey differed very much among countries. The top ten countries in descending order of the absolute number of responses were Italy, the UK, Belgium, Germany, Portugal, Switzerland, Slovenia, the Czech Republic, Romania, and Spain. The subsequent detailed evaluation focuses on these countries in order to ensure significance of the results.

Sufficient participation of industry employees was a great concern. About $72 \%$ of the industry participants came from large enterprises, $27 \%$ came from small and medium-sized enterprises and $2 \%$ came from associations/platforms. About $8 \%$ of all industry participants indicated that their employer started as a spin-off.

The European employment survey addressed both chemists and chemical engineers. They answered the same questionnaire, and their responses were evaluated jointly. Subsequently, we call this joint group of chemists and chemical engineers "chemists" for short. Similarly, the term "analytical chemist" will refer to graduates with their highest degree in analytical chemistry. It will be especially emphasized if the discussion refers not to graduates but to those working as an analytical chemist-regardless of in which subdiscipline they received their highest qualification. 
Table 1 Participants obtained their highest degree in these chemical subdisciplines

\begin{tabular}{ll}
\hline Subdiscipline & Proportion (\%) \\
\hline Organic chemistry & 19 \\
Chemical engineering & 15 \\
Analytical chemistry & 15 \\
General chemistry & 11 \\
Physical chemistry & 9 \\
Inorganic chemistry & 8 \\
Material chemistry & 5 \\
Biochemistry & 5 \\
Polymer chemistry & 4 \\
All others & 9 \\
\hline
\end{tabular}

\section{Education in analytical chemistry}

Analytical chemistry is one of the top three specializations for chemists across Europe (Table 1). The top three specializations are organic chemistry, chemical engineering and analytical chemistry. The preference for a particular degree differs significantly between subdisciplines. Analytical chemists are the largest group among those with a bachelor degree as the highest qualification. At master level, chemical engineers are the largest group; at doctorate level, the majority are organic chemists (Table 2). Other degrees are not considered here because of the distinctly smaller number of responses.

The median age of those who obtained their highest qualification in analytical chemistry is 38 years (the same median age as for all participants) (Fig. 1). Fortyfive per cent of analytical chemists are women (all participants, $39 \%$ ).

This survey is the first of its kind in Europe. For this reason some of the results have to be treated with care. Clearly, such an example is the share of analytical chemists within the top ten responding countries. Compared with the average share of $15 \%$ for all analytical chemists across Europe (Table 1), Italy shows a slightly larger share (19\%; Table 3), but the value for Spain is unbelievably low $(2 \%)$. The reason is apparently related to the very

Table 2 Shares of degree holders for the top three chemical subdisciplines in Table 1

\begin{tabular}{llll}
\hline & Bachelor (\%) & Master (\%) & Doctorate (\%) \\
\hline Organic chemistry & 16 & 32 & 43 \\
Chemical engineering & 23 & 58 & 13 \\
Analytical chemistry & 29 & 42 & 22 \\
\hline
\end{tabular}

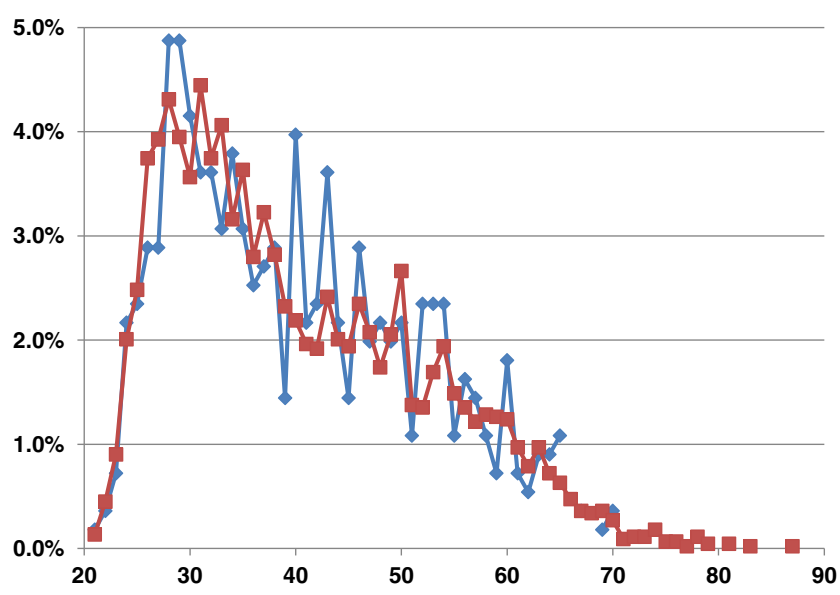

Fig. 1 Age distribution of all chemists (brown) and analytical chemists (blue)

strong Spanish Society for Analytical Chemistry, which practically hosts all Spanish analytical chemists but did not participate in the survey. This kind of fluctuation will certainly disappear in future surveys.

\section{Qualification of analytical chemists}

Most of the analytical chemists in Europe hold a master degree (43\%), followed by the group holding a doctoral degree (38\%). As could be expected, the median age of the doctoral degree holder is higher than that of the master degree holder (Table 4). On the other hand, bachelors do not seem to be younger than masters. For the validity of such conclusions, it has to be taken into consideration that the share of bachelors is distinctly lower than that of the other two groups. For all other degrees ( $4 \%$ of all analytical chemists), the available data were insufficient for them to be included here.

Table 3 Share of analytical chemists in the top ten responding countries

\begin{tabular}{ll}
\hline Country & Share (\%) \\
\hline Italy & 19 \\
UK & 15 \\
Belgium & 12 \\
Germany & 12 \\
Portugal & 6 \\
Switzerland & 7 \\
Slovenia & 14 \\
Czech Republic & 16 \\
Romania & 15 \\
Spain & 2
\end{tabular}


Table 4 Shares of degree holders for graduates in analytical chemistry

\begin{tabular}{lllll}
\hline Qualification & $\begin{array}{l}\text { Share } \\
(\%)\end{array}$ & $\begin{array}{l}\text { Median age } \\
\text { (years) }\end{array}$ & $\begin{array}{l}\text { Women } \\
(\%)\end{array}$ & $\begin{array}{l}\text { Working in native } \\
\text { country }(\%)\end{array}$ \\
\hline Bachelor & 15 & 36 & 46 & 95 \\
Master & 43 & 35 & 48 & 92 \\
Doctorate & 38 & 40 & 43 & 82 \\
$\begin{array}{c}\text { All analytical } \\
\text { chemists }\end{array}$ & 100 & 38 & 45 & 89 \\
\hline
\end{tabular}

Table 5 Percentage of women in analytical chemistry who occupy a particular job type

\begin{tabular}{lllll} 
Qualification & $\begin{array}{l}\text { Women with } \\
\text { a full-time } \\
\text { permanent } \\
\text { contract (\%) }\end{array}$ & $\begin{array}{l}\text { Women with } \\
\text { a temporary } \\
\text { full-time } \\
\text { contract (\%) }\end{array}$ & $\begin{array}{l}\text { Women with } \\
\text { a permanent } \\
\text { contract }(\%)\end{array}$ & $\begin{array}{l}\text { Women with } \\
\text { a temporary } \\
\text { part-time } \\
\text { contract (\%) }\end{array}$ \\
\hline Master & 37 & 63 & 75 & 75 \\
Doctorate & 34 & 64 & 75 & 80 \\
\hline
\end{tabular}

The overwhelming majority of analytical chemists work full-time (85\%). Sixty-six percent of all analytical chemists have a permanent contract, and $14 \%$ have a temporary contract. The percentage of women with a particular job type is significantly higher among those working part-time and among those with a temporary contract (Table 5).

\section{Jobs for analytical chemists}

In what employment sectors do graduates in analytical chemistry find a job? By and large, they find a job in the same employment sectors as all other chemists (Table 6). A more detailed look indicates a slightly higher job density for analytical chemists in research institutes and in the public sector, and a distinctly lower share in manufacturing industry.

Table 6 Employment sectors for chemists and analytical chemists

\begin{tabular}{lll}
\hline & Chemists (\%) & $\begin{array}{l}\text { Analytical } \\
\text { chemists (\%) }\end{array}$ \\
\hline Industry, manufacturing & 32 & 24 \\
Research institute & 19 & 21 \\
Higher education & 17 & 15 \\
Industry, non-manufacturing & 10 & 12 \\
National government or public & 8 & 13 \\
$\quad$ sector & $14 \%$ & $15 \%$ \\
Others & & \\
\hline
\end{tabular}

Table 7 Chemical subdiscipline dominating current jobs of analytical chemists (only top-ranked subdisciplines are shown)

\begin{tabular}{ll}
\hline Subdiscipline & Proportion (\%) \\
\hline Analytical chemistry & 60 \\
Environmental chemistry & 9 \\
General chemistry & 4 \\
Materials chemistry & 3 \\
Pharmaceutical chemistry & 3 \\
Food chemistry & 3 \\
Chemical engineering & 2 \\
Chemical education & 2 \\
\hline
\end{tabular}

Very interesting is the comparison of the preferred specialization listed in Table 1 (organic chemistry $19 \%$, chemical engineering $15 \%$, analytical chemistry $15 \%$ ) with the current jobs of all participants. The top three subdisciplines remain the same as above, but their order changed surprisingly. The response to the question "Which chemical subdiscipline is dominating your current job?" yielded: analytical chemistry (17\%), chemical engineering ( $9 \%$ ), and organic chemistry (9\%). This reveals a larger demand from the job market for analytical chemists than the supply by higher education institutions. The ACS survey [1] has produced the same result for many years.

Those who graduated in analytical chemistry responded very differently to the same question ("Which chemical subdiscipline is dominating your current job?"). The top subdisciplines - i.e. the most promising job areas - for analytical chemists are summarized in Table 7.

\section{Job satisfaction of analytical chemists}

Job satisfaction with the chosen profession or with the current job is complex to interpret. The responses to the corresponding questions were overwhelmingly positive (Table 8). If we

Table 8 Satisfaction of graduates in analytical chemistry with their current job

\begin{tabular}{lllll}
\hline & $\begin{array}{l}\text { My job is } \\
\text { related to } \\
\text { my field } \\
(\%)\end{array}$ & $\begin{array}{l}\text { My job is } \\
\text { commensurate } \\
\text { with my training } \\
(\%)\end{array}$ & $\begin{array}{l}\text { My job is } \\
\text { challenging } \\
(\%)\end{array}$ & $\begin{array}{l}\text { My job } \\
\text { meets my } \\
\text { expectations } \\
(\%)\end{array}$ \\
\hline Very much & 51 & 41 & 41 & 24 \\
Yes & 31 & 35 & 39 & 34 \\
Somewhat & 12 & 18 & 12 & 24 \\
Not at all & 4 & 4 & 5 & 16 \\
No & 1 & 1 & 2 & 3 \\
opinion & & & & \\
\hline
\end{tabular}


combine the rows with positive responses ("very much" and "yes"), we find roughly $80 \%$ job satisfaction — except for the question concerning the expectations of the current job. Slightly less than $60 \%$ see their expectations fulfilled.

Job satisfaction is usually related to advancement in position. Thirty-eight per cent of analytical chemists currently occupy management positions. Recruitment of new staff is a task for $28 \%$ of analytical chemists. Both values are marginally lower than the ones reported for all participants.

Acknowledgments The survey was initiated and executed by the European Chemistry Thematic Network Association (ECTN) [2]. Development of the questionnaire, its translation into 24 European languages, and the Web-based data collection were commissioned by the Joint Research Centre of the European Commission [3]. The project was actively supported by the European Association for Chemical and Molecular Sciences (EuCheMS) [4]. EuCheMS currently has approximately 160,000 individual members organized in 41 national member societies. Those societies who agreed to participate in the survey account for approximately $90 \%$ of the EuCheMS membership. The survey was supported the European Chemical Industry Council (CEFIC) [5]. Some tasks were completed by the European Chemistry and Chemical Engineering Education Network (EC2E2N) [6].

\section{References}

1. http://cen.acs.org/articles/92/i22/Starting-Salaries.html. Accessed 22 Jul 2014

2. www.ectn-assoc.org. Accessed 22 Jul 2014

3. https://ec.europa.eu/jrc/institutes/irmm/. Accessed 22 Jul 2014

4. http://www.euchems.eu/. Accessed 22 Jul 2014

5. http://www.cefic.org. Accessed 22 Jul 2014

6. http://www.ec2e2n.net. Accessed 22 Jul 2014

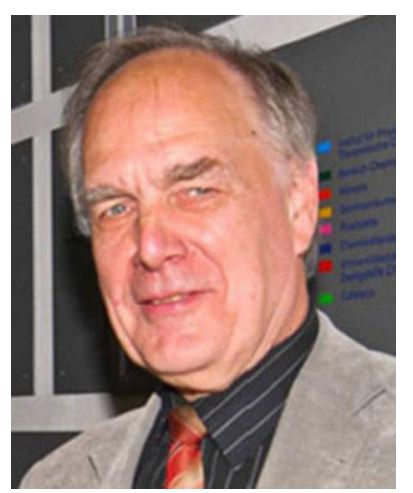

Reiner Salzer retired as Professor of Analytical Chemistry at the Technische Universität Dresden, Germany, in 2007. His main scientific interests include molecular monitoring for early diagnosis of diseases, integration of biologically active functions into polymers, and electronic media in university education. Professor Salzer has authored 14 patents in different fields of analytical chemistry, and over 250 books and scientific publications. Professor Salzer has been elected on to a variety of national and international boards. He is a member of the Norwegian Academy of Science, a recipient of several national and international medals. He served as President of the Division Analytical Chemistry of the German Chemical Society, and is National Delegate to the Division of Analytical Chemistry of EuCheMS, where he is Head of the Study Group Education. He is Chairman of the ECTN Label Committee for the Chemistry Eurolabels.

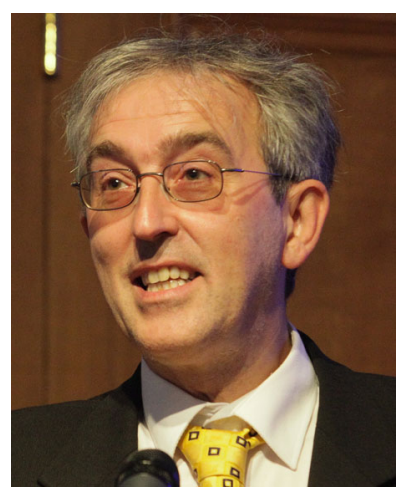

Philip Taylor works for the European Commission Joint Research Centre. He heads a unit dealing with Knowledge Transfer and Standards for Security. $\mathrm{He}$ has a keen interest in quality assurance of analytical measurements. He started the Life Long Learning programme TrainMiC® and initiated the International Master Programme Measurement Science in Chemistry, which received the ECTN Euromaster Label in 2008 .

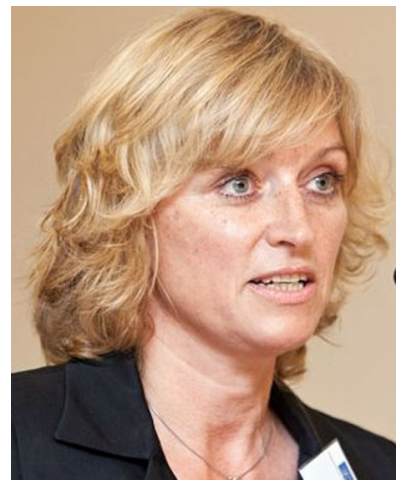

Nineta Macjen is presently Secretary General of EuCheMS. Her scientific interests are analytical chemistry, metrology, quality of measurement (analytical) results.

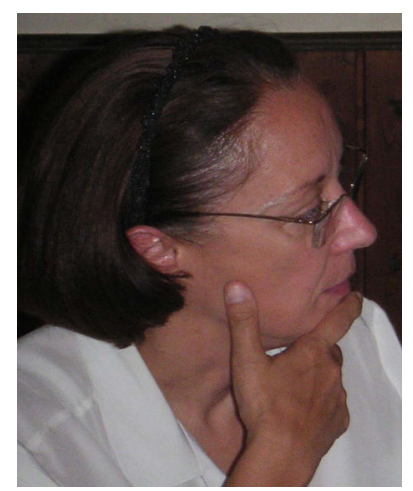

Evangelia A. Varella is Professor at the Department of Chemistry, Aristotle University of Thessaloniki, Greece. Among other things, she is also past president of the European Chemistry Thematic Network (ECTN); educational coordinator of the Greek EChemTest Testing Centre, ECTN; executive secretary of the Euro Label Committee, ECTN; co-ordinator of the Intensive Schools on Conservation Science and Key Competences for Scientists, ECTN. Member of the Management Committee, Tuning Academy; Vice president of the European Alliance for Subject-Specific and Professional Accreditation and Quality Assurance. E. Varella is has also co-ordinated approximately twenty national and European projects on conservation science and on educational issues projects. 


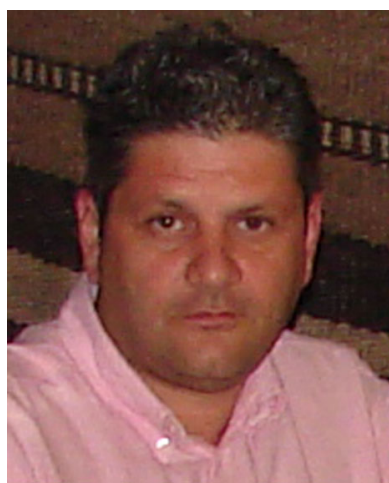

Ioannis Kozaris has a $\mathrm{PhD}$ from the Department of Chemistry at the Aristotle University in Thessaloniki (AUTh), Greece He completed his MSc studies in didactics of chemistry there, and also ICT applications in teaching at the Hellenic Open University. He is a senior researcher in the Department of Chemistry at AUTh and also an ICT expert at the eChemTest Testing Centre, AUTh. He is responsible for the conservation science virtual campus at AUTh. He is also responsible for curriculum development of TEMPUS projects in Jordan and Morocco. 